\title{
Effect of Thermoelectric Cooling (TEC) module and the water flow heatsink on Photovoltaic (PV) panel performance
}

\author{
A.R. Amelia ${ }^{1, *}, M A$ Jusoh $^{1}$, and Ida Shamira Idris ${ }^{1}$ \\ ${ }^{1}$ Centre of Excellence for Renewable Energy (CERE), School of Electrical System Engineering, University Malaysia Perlis, Malaysia
}

\begin{abstract}
Photovoltaic (PV) panel suffers in low conversion efficiency of the output performance affected by the elevated operating temperature of the PV panel. It is important to keep the PV panel to operate at low temperature. To address this issue, this paper proposes the cooling system using thermoelectric cooling (TEC) and water block heatsink for enhancing the PV panel output performance. These both types cooling system were designed located on the back side of the PV panel to cool down the operating temperature of the PV panel. To evaluate the function for the existing cooling systems, the experiment was subsequently performed for PV panel without and with different design of the cooling system in outdoor weather conditions. By comparing the experimental results, it is concluded that by the hybrid cooling system which combining TEC module and the water block heatsink could improve the output performance of the PV panel. By the reduction temperature of the PV panel by $16.04 \%$, the average output power of the PV panel has been boosted up from $8.59 \mathrm{~W}$ to $9.03 \mathrm{~W}$. In short, the output power of the PV panel was enhanced by the reduction of the operating temperature of the PV panel.
\end{abstract}

\section{Introduction}

Nowadays, the rapid incorporation of renewable energy technologies within the global energy supply infrastructure growing demand, due to the surging oil prices and increasing environmental awareness. Especially, solar energy with clean energy source, renewable and environmental-friendly is received attention. Solar energy is artificially extracted in the forms of electricity and heat [1]. However, the actual performance of solar energy is still below its actual efficiency. The weakness is that the unemployed infrared energy is converted into waste heat, leads to the rising operating temperature of the PV panel. Increasing of the operating temperature causes the efficiency of PV panel decreases [2]. Therefore, application cooling system on a PV panel is required to enhance the efficiency.

Various methods can be employed to achieve cooling action for PV panels. Water cooling is a favorable for cooling PV panel, mostly integrated using the water spray [3]. D. Kim et al. employed the water circulation over the surface PV panel in improving its outputpower. There is about $11.6 \%$ increasing in maximum powers when attached cooling system on a PV panel. Moreover, the extra power can be generated when the existing water flow removed the particles that interfere with solar radiation from the surface cell [4]. T. Chinamhora et al. cools the back and front PV panel by using the water coolant then compared to the PV panel without cooling system. The measured results indicated the electrical efficiency increases around 10-22\% when using watercoolant during summer day, unfortunately decreased to 3-20\% on cloudy days [5]. Y.M.Irwan et al. investigates the effect of water cooling using DC pump under indoor testing. Under different level of solar radiation, the water cooling was observed to be performed rather than PV panel without cooling system when about 9-22 \% increasing in output power. The increasing in output power caused by the reduction of PV panel temperature [6].

Recently, the hybrid system involves the combination of TE and PV technology also attracted as an alternative method for enhancing conversion efficiency by cooling the PV panels. A standard TE module utilizes the Seebeck effect composed of several tens to hundreds of pairs of thermocouples connected together electrically in series and thermally in parallel [7]. TE module can operate as a heat pump or providing heating or cooling. Research on PV panel with TE modules, such as Kane and Verma [8] proved that the hybrid system by combining the PV panel thermoelectric can be operated at PV panel temperature of $53{ }^{\circ} \mathrm{C}$. From this review paper, the results show that the PV panel can operate at elevated operating temperature without loss of the output power. Besides that, the efficiency of the PV panel also had been improved when PV panel was cooling at the temperature of $10^{\circ} \mathrm{C}$. Park et al. investigated the effect of 2-wire hybrid configuration on conventional crystalline silicon of PV cells. The experimental results indicate the importance of accurate internal resistance between the PV cells and TE devices, contributes to output power increase ranging from $30 \%$ to $250 \%$ [9]. Recently, Alomair et al. [10] investigated the PV/TE airconditioning system for remote area application through a theoretical and experimental. They stated that by using $\mathrm{PV} / \mathrm{TE}$ air-conditioning system to cool space is possible.

*Corresponding author: amelia_razak87@yahoo.com 
It is because the desired temperature may be achievable if the size and capacity of the TEC are well-designed.

In this present work, the TEC and water cooling system have been proposed in order to improve the output performance of the PV panel. These both devices act as the cooling system to reduce the PV panel temperature by extracting the excesses heat. Different design of cooling system also has been compared with the same type of the PV panel. Section 2 explains materials used in the experimental study. This section also presents the methodology of the experiment. Section 3 analyses and discussed briefly on the results produced. Meanwhile, the last section shows the conclusion of this proposed study.

\section{Methodology}

\subsection{Material preparation}

\subsubsection{PV panel}

For the purpose of the present work, a polycrystalline silicon PV panel with the rating power of $10 \mathrm{~W}$ has been used. With the surface area of $0.105 \mathrm{~m}^{2}$, this PV panel able to generate the open-circuit voltage boost to 18.72 $\mathrm{V}$, meanwhile 0.59 A for short-circuit current.

\subsubsection{TEC module}

In this study, the TEC module was used as an alternative method to reduce the operating temperature of the PV panel. In Table 1, the specification data for the use of the TEC module are listed. As showed in this table, the typical TEC module is made of Bismuth Telluride (Bi2Te3) based alloy which known as the most commercial module in TEC market [11]. Through Table 1 , it shows that the selected TEC module which was constructed by 127 numbers of thermocouples can generate $6 \mathrm{~A}$ of maximum current and $15.2 \mathrm{~V}$ for the maximum voltage. Besides that, this TEC module is operated at $12 \mathrm{~V}$ of a direct current (DC).

Table 1. The specification of TE module.

\begin{tabular}{|c|c|}
\hline Specifications & Data \\
\hline Model & TEC1-12706 \\
\hline Material & Bismuth Telluride $\left(\mathrm{Bi}_{2} \mathrm{Te}_{3}\right)$ \\
\hline No. of thermocouples & 127 \\
\hline Dimension module & $40 \times 40 \times 4.3 \mathrm{~mm}$ \\
\hline Maximum current & $6 \mathrm{~A}$ \\
\hline Maximum voltage & $15.2 \mathrm{~V}$ \\
\hline Operational voltage & $12 \mathrm{~V}(\mathrm{DC})$ \\
\hline
\end{tabular}

\subsubsection{Water block heatsink}

Water is the best coolant naturally available with the high heat capacity when compared to the air cooling system [12]. Therefore, the water block heatsink is used to cool down the operating temperature of the PV panel. Besides that, this present work also used the water block heatsink as the coolant to cool down the cool side of the TEC module. Water is flowing through the channels such shown in Figure 1. The water from inlet will flow across the heatsink block, the structure design of the heatsink affects the water circulation process.

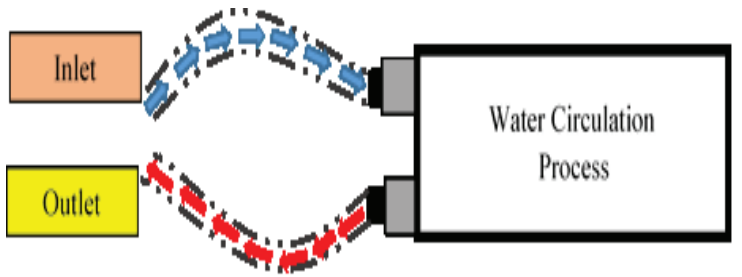

Fig. 1. Flow of water in water block heatsink.

\subsection{System description and experimental setup}

In order to evaluate the effect of cooling systems for heat extraction from the PV panel, four different systems were investigated. Schematic diagrams and experimental setup for four different systems are shown such in Figure 2. Figure 2 (a) is represented for PV panel without a cooling system. Meanwhile, Figure 2 (b) shows the diagram of PV panel with TEC modules. Figure 2 (c) consists of a PV panel cooled by the only water block heatsink. Lastly, Figure 2 (d) represents for the PV panel using a hybrid system which combining the TEC module and water block heatsink as the cooling system. In analyzing all different cases, the experiment was conducted in a sunny day from 11.30 a.m. to 2.15 p.m. under outdoor condition.

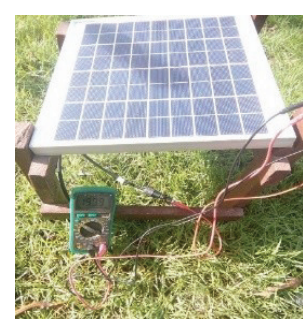

(a)

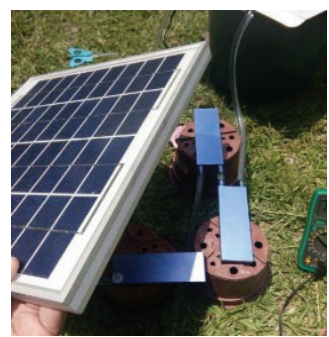

(c)

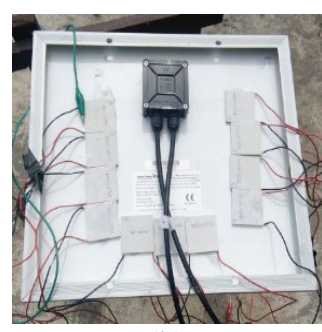

(b)

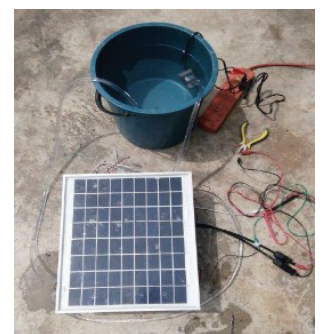

(d)
Fig. 2. Different cases of the experiment under outdoor condition; (a) Without cooling, (b) With TEC module, (c) With water block heatsink, (d) With TEC and water block heatsink. 


\section{Experiment results}

In analyzing the distribution of temperature, all recorded hot surface and cold surface temperature were plotted. The hot surface TE module and operating temperature of the PV panel are supposed to be equal since thermocouple was attached on the backside of the PV panel. The operating temperature of hot surface curves, obtained following the analysis of experimental results, is presented in Figure 3. Observing this figure, the variation in temperature were produced caused by the different design of the cooling system integrated on the PV panel. In more details, the highest average of the hot surface temperature is $56.03{ }^{\circ} \mathrm{C}$ for PV panel without a cooling system. On the other hand, when hybrid cooling system (TEC with water block heatsink) is taken into consideration, a significant temperature drop was observed compared to other cooling system. There was about the reduction by $16.04 \%$ when this cooling system was integrated on a PV panel. The average of the hot surface temperature for this case is $47.04{ }^{\circ} \mathrm{C}$.

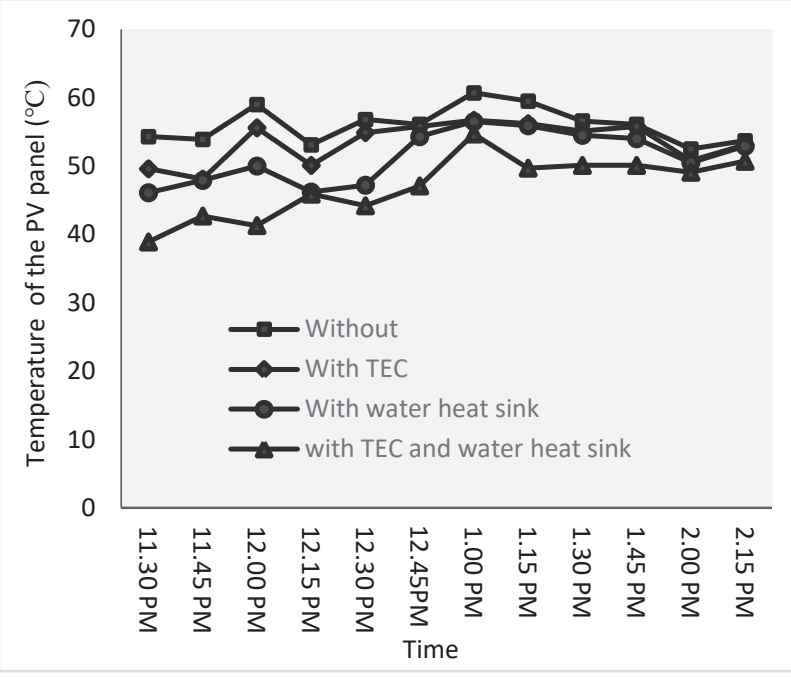

Fig. 3. Operating temperature of the PV panels.

Figure 4 shows the open-circuit voltage produced from each case of experiment. Based on this figure, the lowest average of open-circuit voltage is produced by a PV panel without a cooling system. The average of open-circuit for this case was determined approximately $19.43 \mathrm{~V}$. In theoretical, the output voltage of the PV panel reduced with the decrease in band gap. The decrease in the band gap is caused by the increase in photon generation, which is influenced by the rising of PV panel temperature [13]. Inversely, the highest average of open-circuit voltage is represented by the PV panel with hybrid cooling system (PV panel with TEC and water heatsink). The open-circuit voltage was increased by $2 \%$ when integrated hybrid cooling system on PV panel. This is due to the reduction temperature of the PV panel, enhances the output performance from PV panel [14].

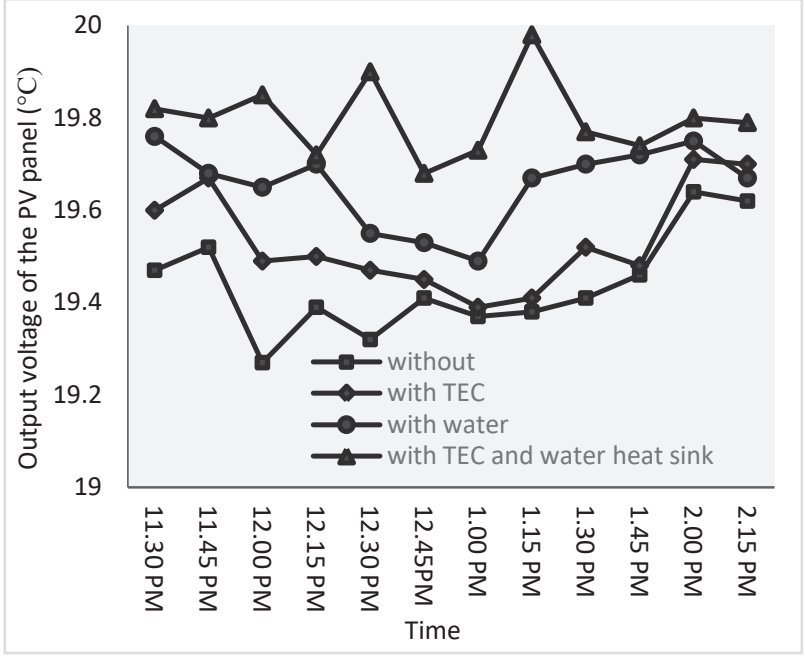

Fig. 4. Open-circuit voltage of the PV panels.

Figure 5 describes the calculated output power by using Equation 1 [15]. The output power of each case was calculated based on distribution operating temperature of the PV panel. By analyzing this figure, the lowest average of the output power is $8.59 \mathrm{~W}$ for PV panel without a cooling system. Conversely, by applying the TEC module as a cooling system, the output power of the PV panel increased by $1.5 \%$, followed by PV panel with water cooling with $2.5 \%$. Meanwhile, the highest average of the output power is represented by a PV panel with attaching TEC module and water as the cooling system. With this hybrid combination, the output power of the PV panel could be increased approximately5.12\%. This is because of the reduction of the operating temperature of the PV panel. This fact is supported by [16] which states that the output power of the PV panel was increased when its operating temperature was decreased.

$$
P_{\text {max }_{\text {corrected }}}=P_{\text {max }_{\text {stc }}} \times\left\{1+\left[\left[\frac{\gamma}{100}\right] \times\left(T_{\text {panel }}-T_{\text {stc }}\right)\right]\right\}
$$

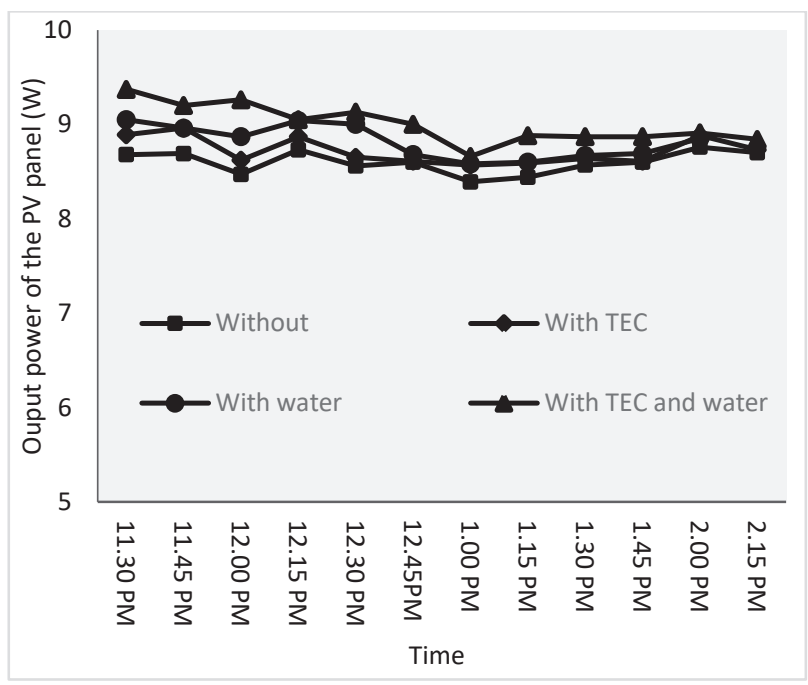

Fig. 5. Output power of the PV panels. 
Figure 6 and Figure 7 present the temperature difference between hot and cold side surface of TEC module. Figure 6 is represents for the PV panel with only TEC module, meanwhile Figure 8 shows the results for PV panel with hybrid system (TE module and water heatsink). By referring to Figure 6, the observation result indicated that there is small differences between hot and cold side surface temperature. The average of cold side temperature was determined by $49.13{ }^{\circ} \mathrm{C}$. Therefore, the average of difference temperature between hot and cold surface was approximately $2.2{ }^{\circ} \mathrm{C}$. Conversely, the difference temperature of TEC module for PV panel with hybrid system such shown in Figure 7 is quite larger with $4.8{ }^{\circ} \mathrm{C}$. The average of cold side temperature of TEC module for this cases was approximately $42.24^{\circ} \mathrm{C}$. The performance TEC could be enhanced with the lower temperature on cold side surface of TEC module. It is because of a high amount of output voltage of TEC can be generated affected by the large temperature difference between the hot side and cold side surface [17].

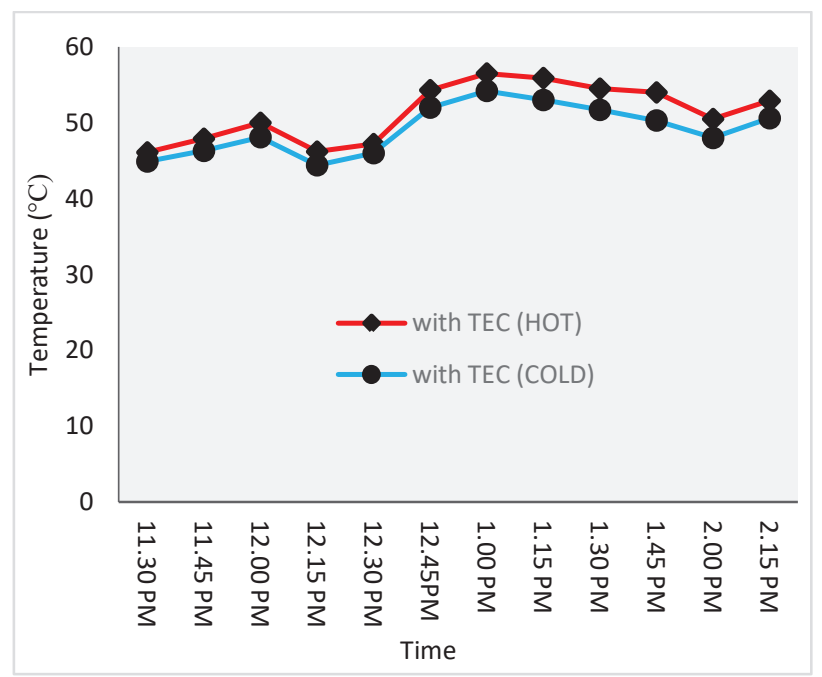

Fig. 6. Temperature difference of TEC module for the case of PV panel with TEC module.

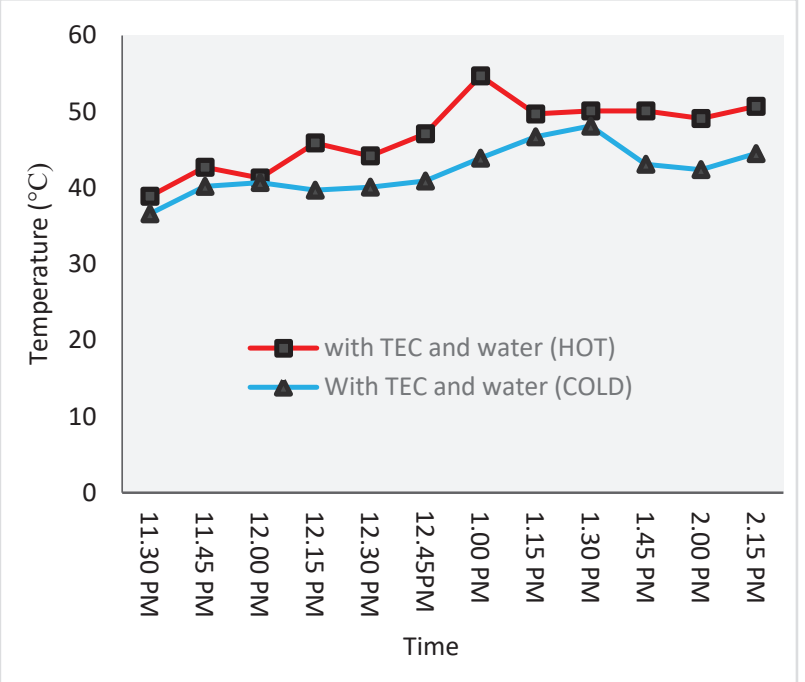

Fig. 7. Temperature difference of TE module for the case of PV panel with TEC module and water heatsink.

\section{Conclusion}

In short, this paper studies the effect of cooling system for PV panel output performance. Different cooling system were integrated on the PV panels to compare their functionality. For the purpose study, the output performance of the PV panel without cooling system was compared with the PV panels which used water block heatsink or TEC modules as the cooling system. The experimental results briefly shows that the elevated operating temperature of the PV panel gives the negative impact on PV panel output performance. From the results, PV panel without cooling system has the lower output power when compared to the PV panel with cooling systems. By developing the hybrid (TE modules and water) cooling system, the output power of the PV panel has increased by $5.12 \%$. This is because of the reduction in operating temperature of the PV panel from $56.03{ }^{\circ} \mathrm{C}$ to $47.04{ }^{\circ} \mathrm{C}$. Therefore, it shows that the existing cooling system makes possible to make PV panel operate at maximum output performance by decreasing the operating temperature of the PV panel.

The authors thank the Fundamental Research Grant Scheme (FRGS) for providing the fund to complete this study.

\section{References}

1. G.K. Singh, Energy, 53, 1-13, (2013)

2. S. Chander, A. Purohit, A. Sharma, Arvind, S.P. Nehra, M.S. Dhaka, Energy Reports, 1, 104-109, (2015)

3. Y. Cui and Q. Zhu, Power and Energy Engineering Conference (APPEEC), (2012)

4. Dong-Jun. K, D.H. Kim, S. Bhattarai and J. Oh, Journal of Solar Energy Engineering, 133, (2011)

5. T. Chinamhora, G. Cheng, Y. Tham and W. Irshad, Proceeding of International Conference on Energy and Sustainability, (2013)

6. Y.M.Irwan , W.Z. Leow, M. Irwanto, Fareq.M, A.R. Amelia, N. Gomesh and I.Safwati, Energy Procedia, 79, 604-611, (2015)

7. U. Pau and P. Adour, Energy Conversion and Management, 140, 167-181, (2017)

8. A.N. Kane and V. Verma, International Journal of Renewable Energy Research, 3, 320-324, (2013)

9. K. Park, S. Shin, A. S. Tazebay, H. Um, J. Jung, A. Jee, M. Oh, S. Park, B. Yoo, C. Yu and J. Lee, Scientific Reports, 3, (2013)

10. M. Alomair, Y. Alomair, S. Mahmud and H.A. Abdullah, Journal of Thermal Science and Engineering Applications, 7, (2015)

11. P. Huen and W.A. Daoud, Renewable and Sustainable Energy Reviews,72, 1295-1302, (2017)

12. K. Moradi, M. Ali Ebadian and C. Lin, International Journal of Heat and Mass Transfer, 64, 483-500, (2013)

13. S. Kumar and D.T. Kumar, International Journal of Innovative Research in Electrical, Electronics, 
Instrumentation and Control Engineering, 2,21682172, (2014)

14. A.A. Hachicha, C. Ghenai and A.K. Hamid, International Journal of Environmental, Chemical, Ecological, Geological and Geophysical Engineering, 9, 999-1002, (2015)

15. T. Ishii, K. Otani, A. Itagaki and K.Utsunomiya, Japanese Journal of Applied Physics, 51, (2012)
16. A.R. Amelia, Y.M. Irwan, M. Irwanto, W.Z. Leow, N. Gomesh, I. Safwati and M.A.M. Anuar, International Journal of Electrical and Computer Engineering, 6, 526-534, (2016)

17. D. Vadhel, S. Modhavadiya and Prof. J. Zala, International Research Journal of Engineering and Technology,4, 1904-1908, (2017). 